\title{
Pap Test Screening among Vertically HIV-Infected Young Women
}

\author{
Hyppolite K. Tchidjou ${ }^{1 \#}$, Nicola Cotugno ${ }^{1,2}$, Giuseppe Pontrelli ${ }^{1}$, Emma C. Manno ${ }^{1}$, Luana Coltella ${ }^{3}$, \\ De Vito Rita ${ }^{4}$, Stefania Baldassari ${ }^{1}$, Vittorio Colizzi ${ }^{5}$, Paolo Rossi ${ }^{1,2}$, Maria C. Lucchetti ${ }^{6}$, \\ Stefania Bernardi ${ }^{1}$
}

${ }^{1}$ University Department of Pediatrics (DPUO), “Bambino Gesù” Children’s Hospital, Rome, Italy; ${ }^{2}$ Chair of Pediatrics, Department of Public Health University of Rome Tor Vergata, Rome, Italy; ${ }^{3}$ Unit of Microbiology, “Bambino Gesù” Children’s Hospital, Rome, Italy; ${ }^{4}$ Unit of Pathology, "Bambino Gesù” Children's Hospital, Rome, Italy; ${ }^{5}$ Department of Biology, University of Rome Tor Vergata, Rome, Italy; ${ }^{6}$ Department of Pediatric Surgery, “Bambino Gesù” Children’s Hospital, Rome, Italy.

Email: "hyppolite.tchidjouku@opbg.net

Received April 16 ${ }^{\text {th }}, 2013$; revised May $16^{\text {th }}, 2013$; accepted June $16^{\text {th }}, 2013$

Copyright (C) 2013 Hyppolite K. Tchidjou et al. This is an open access article distributed under the Creative Commons Attribution License, which permits unrestricted use, distribution, and reproduction in any medium, provided the original work is properly cited.

\section{SUMMARY}

Background: The risk of Human Papillomavirus (HPV) infection and cervical cancer has increased in Human Immunodeficiency Virus (HIV) infected women. Several other Genital Infections (GI), have been shown to act as risk factors for the acquisition of HPV infection and for the development of cervical cancer. Methods: In this observational study, we evaluated the prevalence of HPV infection, GI and cervical abnormalities among vertically HIV-infected young women in the early years of sexual activity. HPV viral strains have been classified as high risk and low risk to develop precancerous and cancerous lesions according to the WHO classification. Results: Eighteen vertically HIV-infected young women and eleven healthy age matched controls were studied. HIV-infected young women showed a higher incidence of high risk HPV genotype infection compared to healthy control. HIV-infected women affected by HPV presented lower levels of CD4 ${ }^{+}$percentages. GI and Pap test did not show any relation with HPV infection and effects were similar in both groups. Conclusion: HIV infection and low $\mathrm{CD}^{+}{ }^{+}$percentages seem to play a key role as risk factors for HPV-infection among HIV-infected young women. Therefore, future efforts will be needed to improve the adherence of HIV-infected young women in HPV pap test screening considering the lower ability of these patients to clear the HPV infection.

Keywords: HPV; HIV; Genital Infections

\section{Introduction}

Human Papilloma Virus (HPV), is a sexually transmitted DNA virus, and has been shown to act as the central etiological agent in the development of cervical cancer [1]. Human Immunodeficiency Virus (HIV) infection in women is associated with an increased risk of HPV-associated malignancies and cervical cancer [2].

The prevalence of cervical neoplasia among HIV-infected women ranges from $11 \%$ to $60 \%$ and increases with the degree of immune suppression $[3,4]$. Furthermore, several other Genital Infections (GI), including Bacterial Vaginosis (BV), Gardnerella, Trichomonas vaginalis (TV), Chlamydia Trachomatis (CT), and geni-

${ }^{*}$ Conflict of Interest: the authors declare no conflict of interest.

${ }^{\#}$ Corresponding author. tal herpes, have been shown to act as risk factors for the acquisition of HPV infection and development of cervical neoplasia [4,5]. Although the majority of healthy young women appear to eliminate HPV within 12 - 40 months from the contact, in a smaller percentage, the intracellular persistence of HPV infection may lead to development of cervical abnormalities and neoplasia $[2,6]$. Furthermore, cervical cytologic abnormalities tend to progress more rapidly to invasive cervical cancer in HIV-infected than non-infected women [2].

The introduction of Papanicolaou (Pap) test in cervical cancer screening programs reduced cervical cancer incidence rates from $90 \%$ to $60 \%$ within three years of implementation [7] permitting an early detection, diagnosis and treatment of cervical cytological abnormalities. According to the increased risk of cervical cancer in 
HIV-infected patients, current guidelines issued by the US Public Health Service and the Infectious Diseases Society of America call for more intensive screening in HIV-infected women $[7,8]$.

However few studies provide specific evidences about the adherence of HIV-infected women to the Cervical Pap Test Screening (CPAP-S) schedule [9,10], the purpose of this study is to report the prevalence of HPV infection, GI and cervical abnormalities among HIV-infected young women in the early years of sexual activity.

\section{Materials and Methods}

A prospective observational study was conducted among a cohort of 110 HIV infected children and adolescents (0 - 26 years old) followed at Bambino Gesù Children Hospital of Rome, Italy.

The study was approved by the local Ethical Committee, and informed consent obtained from the patients and parents or guardians of all participants.

Between June 2008 and November 2011, 18 vertically HIV-infected young women (16 - 25 years old) and 11 HIV-negative young women (14 - 26 years old) who required routine gynaecologic evaluation and Pap test examination were enrolled.

An interview investigating the sexual behaviours in terms of number of partners, years of sexual activity and use of contraception was made to all participants. The two study groups were comparable for age and sexual behaviours and no patients received HPV vaccination before the CPAP-S. The patients with more than 2 partners or who had sex more than 24 months before were excluded from the study.

During the gynaecologic evaluation, a vaginal examination with cervical Pap test and vaginal swabs has been performed to all patients. $\mathrm{CD} 4{ }^{+} \mathrm{T}$ cells count and plasma HIV viral load, were obtained from the blood samples of HIV-infected patients. All HIV-infected patients were classified according to Centers for Disease Control and Prevention (CDC) and all of them except one were on Highly Active Antiretroviral Treatment (HAART). Two patients showed a $\mathrm{CD} 4^{+}$cell count lower than 200
cells/mL, and 5 had $\mathrm{CD}^{+}$between 200 and $500 / \mathrm{mL}$. Regarding the HIV viral load, only 5 patients had $>50$ copies/mL.

Young woman underwent vaginal examination by use of a speculum because all patients were sexually active. Swabs of vaginal fluid were obtained using gram stain criteria [11], using wet mount or culture; a cervical sample obtained by use of a Weck-Cel sponge (Xomed Surgical Products), a $10-\mathrm{mL}$ cervical vaginal lavage (CVL) for testing for HPV infection; and an endocervical sample for testing for Chlamydia trachomatis and Neisseria Gonorrhoea infection [12].

Cervical cytological specimens were evaluated by the pathologist and were classified according to the 2001 Bethesda system which uses the following classifications for reporting cervical cytologic results: normal, atypical squamous cells (ASC), low-grade squamous intra epithelial lesions (LSIL), high-grade squamous intra-epithelial lesions (HSIL), and squamous cell carcinoma (SCC) [13]. The level of risk of HPV genotype was considered according to the classification of Muñoz (2003) [14]. Fifteen HPV genotypes were classified as high-risk types (16, 18, 31, 33, 35, 39, 45, 51, 52, 56, 58, 59, 68, 73, and 82); 3 were classified as probable high-risk types (26, 53, 66,73 , and 82 ); and 12 were classified as low-risk types (6, 11, 40, 42, 43, 44, 54, 61, 70, 72, 81, and CP6108).

Data analysis was conducted with GraphPad Prism 5.0 for Windows (GraphPad Software, San Diego California USA). Statistical analysis of baseline variables was carried out for continuous data with either ANOVA method for Analysis of Variance for normal distributed data, or Mann-Whitney test for non-normal distributed data. Prevalence of HPV-infection (high and low risk types) was compared between HIV-infected and uninfected with chi-square or Fisher test when appropriate. A value of $p<0.05$ was considered statistically significant.

\section{Results}

Eighteen HIV-infected women (16 - 25 year old) and 11 healthy controls (14 - 26 year old) were studied (Table 1). All patients have had less than 2 partners before and

Table 1. Baseline characteristics of the patients, overall HIV infected and uninfected woman.

\begin{tabular}{ccccc}
\hline & Total $(\mathrm{n}=29)$ & HIV Infected Women $(\mathrm{n}=18)$ & Healthy Control $(\mathrm{n}=11)$ & $\mathrm{p}$ \\
\hline Age mean (SD) & $20.03( \pm 3.48)$ & $20.33( \pm 2.45)$ & $19.55(4,82)$ & - \\
Ethnicity n (Africa) & 1 & 1 & - & 0.53 \\
CDC Status (A/B/C) & - & $7 / 2 / 9$ & $4(36 \%)$ & $0.29^{*}$ \\
Infection at Vaginal Smear n (\%) & $15(51 \%)$ & $11(61 \%)$ & $3(27 \%)$ & $0.38^{*}$ \\
Presence of External Genital Warts n (\%) & $11(38 \%)$ & $8(44 \%)$ &
\end{tabular}

SD: Standard Deviation; p value calculated with ANOVA or with Mann Whitney test $\left(^{*}\right)$ and was referred to comparison between HIV infected women and healthy controls. 
sexual experience was less than 24 months from CPAP-S, moreover contraception use was referred to be not routinely in all participants.

Fifty percent of the HIV-infected women, and 27\% among the healthy control were positive for HPV. All HIV-infected women resulted positive for HPV infection were affected by high-risk HPV genotypes (58, 59, 31, $84,66,51,52$, and 16), on the other hand in the control group only 1 patient among the 3 resulted HPV infected presented an high risk genotype (Figure 1).

Thus HIV-infected young women showed an higher incidence of high risk HPV genotype infection compared to healthy control ( $p=0.029$ ), moreover HIV-infected women affected by HPV presented lower levels of CD4 ${ }^{+}$ percentages $(p=0.024)$ (Figure 1$)$.

The HPV infection with more than 1 genotype was present in the $66.6 \% \mathrm{HIV}$-infected group, however none of the HPV-infected patients in the control group presented multiple HPV genotype. Fifteen patients between the 2 groups resulted positive for GI, however any relation to HPV or HIV infection was found in both groups.

No differences were found between the HPV infected and uninfected patients in terms of age, ethnicity and CDC status (supplementary data). Moreover, among HIV infected women no relation was found with HIV-RNA levels, CD4 cell counts and HPV infection (Figure 1).

Sixty one percent of the HIV-infected women and $36 \%$ of the healthy controls showed GI at the vaginal smear, however the analysis of the prevalence of GI among the 2 groups did not show any significant difference. Moreover any difference was found in the prevalence of GI between HPV infected and HPV uninfected women in all patients ( $p>0.05)$.

In addition, the analysis of the cervical cytological specimens did not show cervical dysplasia or SIL I in both groups.

\section{Discussion}

Previous studies conducted on adult women have shown that HPV infection risk increased among HIV-infected women compared to healthy controls [9,14-17]. In addition, besides HIV infection, low $\mathrm{CD}^{+}$cell count and High HIV-RNA level were found to be correlated to HPV-infection risk and cytological abnormalities [18]. In the present study, we confirm that the natural history of HPV is altered by HIV-infection, even in younger women who are in the early stages of HIV infection and in the first years of their sexual experience. In our cohort we found that the prevalence of HPV infection was higher among HIV-infected than an age matched healthy group of women similar in terms of sexual behavior. Notably, although detection of HPV infection may represent initial acquisition, considering the young age at the time of PAP-S, our analysis does not clarify whether it is caused by a higher susceptibility of new infection or if it is due to viral reactivation in HIV-infected young women
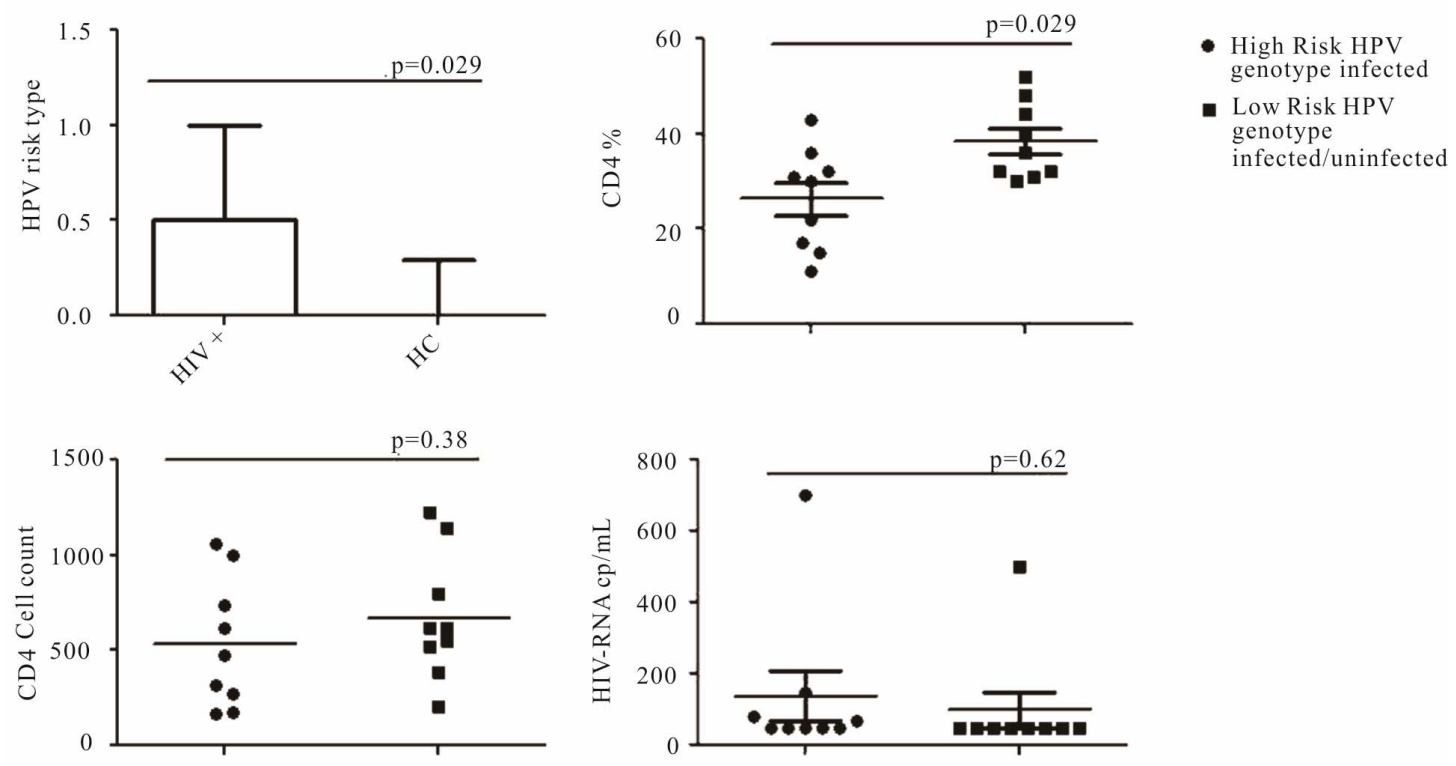

Figure 1. HPV genotype risk infection in HIV infected women versus healthy control (upper left side graph). An arbitrary value of " 0 " was assigned to the low risk HPV genotype and HPV negative patients, and a value of " 1 " to the high risk genotype. Median with range is shown in the bar plot. Level of $\mathrm{CD4}^{+}$number (\#) and percentage (\%) and HIV Viral Load (HIV-RNA) in HIV infected patients grouped according to the level of HPV genotype infection risk. CD4 (\%, upper right graph; \#, lower left side graph), and Viral Load (lower right side graph) data are referring only to HIV infected patients. Mean and Standard Deviation are shown in the dot plots. 
who are not able to release the HPV infection.

We found that $\mathrm{CD}^{+}$lymphocyte percentage, consistently with previous studies, was strongly associated with high risk of HPV infection [19]. These data suggest that HPV progression and regression is influenced by HIVinfection, depending on the severity of the diseases and immune depression.

According to this, the dysfunction caused by HIV infection seems to be related to the presence of HPV types from multiple HPV subgroups. In line with previous data [20], in our cohort the $66.6 \%$ of the HIV-infected patients and none of the HIV-uninfected women presented a multiple subgroup of HPV-infection. These evidences show that a dysfunction in the immune response favours the persistence of HPV infection resulting in a higher probability for HIV-infected individuals, who remain sexually active, to acquire new HPV types compared to HIV-uninfected girls who rapidly clear HPV after each infection. We did not find cervical dysplasia or SIL (Squamous Intraepithelial Lesion) in both groups of subject, this is probably due to the shorter exposure to HPV, according to younger age of our patients compared to adult women.

Although previous data show that HPV infection may favour changes in the vaginal milieu that facilitate development of GI, any relation between GI, HPV infection, and HIV $[15,21]$ was observed. This is in contrast with some previous data which show that women with GI may be more susceptible to the acquisition or reactivation of HPV infection and this could be due to their increased production of sialidase and resultant changes in the cervical mucous barrier, decreased production of $\mathrm{H}_{2} \mathrm{O}_{2}$ and changes in production of cytokines [22,23]. However literature is contrasting and controversial about this topic and two other studies didn't find an increased rate of GI in women with HPV, compared with women without HPV [19,22,23].

Although our study is hampered by the low number of patients, our findings provide evidence that HIV-infected young women present a higher risk to be infected by HPV depending on their immune status, highlighting the need for further research to better understand the physiology of the female genital tract and the local response to pathogens, especially in the vertically HIV-infected young women.

In conclusion, $\mathrm{HIV}$ infection and low $\mathrm{CD}^{+}$are the main risk factor for HPV high-risk types infection. Therefore, future efforts will be needed to define clearer guidelines for diagnosis and management of HPV-infection in HIV-infected young women. Such guidelines, should consider not only gynecologic examination and vaginal swabs, but include also a CPAP-S.

Finally, according to the high prevalence of HPV in HIV-infected young women, new vaccine trials for pre- vention of HPV-infection should be designed for all HIV-infected adolescents considering the vaccination even for their partners.

\section{Acknowledgements}

The authors acknowledge the contributions of the NEAT (European AIDS Treatment Network) project-LSHP-CT2006-037570. We would like to acknowledge all the patients who participated in this study. We want to acknowledge Mr Emiliano Cotugno for the English review of the manuscript.

\section{REFERENCES}

[1] J. Palefsky, "Human Papillomavirus Infection in HIVInfected Persons," Topics in HIV Medicine, Vol. 15, No. 4, 2007, pp. 130-133.

[2] J. Kravchenko, I. Akushevich, S.L. Sudenga, C. M. Wilson, E. B. Levitan and S. Shrestha, "Transitional ProbabilityBased Model for HPV Clearance in HIV-1-Positive Adolescent Females,” PLoS ONE, Vol. 7, No. 1, 2012, p. e30736. doi:10.1371/journal.pone.0030736

[3] T.V. Ellerbrock, M.A. Chiasson, T.J. Bush, X.W. Sun, D. Sawo, K. Brudney and T. C. Wright, "Incidence of Cervical Squamous Intraepithelial Lesions in HIV-Infected Women," Journal of the American Medical Association, Vol. 283, No. 8, 2000, pp. 1031-1037. doi:10.1001/jama.283.8.1031

[4] R. Setse, G. K. Siberry, W. J. Moss, P. Gravitt, T. Wheeling, B. Bohannon, K. Dominguez and Legacy Consortium, "Cervical Pap Screening Cytological Abnormalities among HIV-Infected Adolescents in the LEGACY Cohort," Journal of Pediatric and Adolescent Gynecology, Vol. 25, No 1, 2012, pp. 27-34. doi:10.1016/j.jpag.2011.09.002

[5] D. C. Boyle, S. E. Barton, S. Uthayakumar, P. E. Hay, J. W. Pollock, P. J. Steer and J. R. Smith, "Is Bacterial Vaginosis Associated with Cervical Intraepithelial Neoplasia?” International Journal of Gynecological Cancer, Vol. 13, No. 2, 2003, pp. 159-163.

[6] C. Mao, J. P. Hughes, N. Kiviat, J. Kuypers, S. K. Lee, D. E. Adam and L. A. Koutsky, "Clinical Findings among Young Women with Genital Human Papillomavirus Infection," American Journal of Obstetrics \& Gynecology, Vol. 188, No. 3, 2003, pp. 677-684.

doi:10.1067/mob.2003.164

[7] D. Saslow, P. E. Castle, J. T. Cox, D. D. Davey, M. H. Einstein, D. G. Ferris, S. J. Goldie, D. M. Harper, W. Kinney, A. B. Moscicki, K. L. Noller, C. M. Wheeler, T. Ades, K. S. Andrews, M. K. Doroshenk, K. G. Kahn, C. Schmidt, O. Shafey, R. A. Smith, E. E. Partridge, F. Garcia and Gynecologic Cancer Advisory Group, “American Cancer Society Guideline for Human Papillomavirus (HPV) Vaccine Use to Prevent Cervical Cancer and Its Precursors,” CA: A Cancer Journal for Clinicians, Vol. 57, No. 1, 2007, pp. 7-28. doi:10.3322/canjclin.57.1.7

[8] Centers for Disease Control and Prevention, K. A. Workowski and S. M. Berman, "Sexually Transmitted Diseases 
Treatment Guidelines,” MMWR-Recommendations and Report, Vol. 55, No. RR-11, 2006, pp. 1-94.

[9] E. A. Stier and A. S. Baranoski, "Human Papillomavirus Related Diseases in HIV-Infected Individuals," Current Opinion in Oncology, Vol. 20, No. 5, 2008, pp. 541-546. doi:10.1097/CCO.0b013e3283094ed8

[10] S. B. Brogly, D. H. Watts, N. Ylitalo, E. L. Franco, G. R. Seage 3rd, J. Oleske, M. Eagle and R. Van Dyke, "Reproductive Health of Adolescent Girls Perinatally Infected with HIV," American Journal of Public Health, Vol. 97, No. 6, 2007, pp. 1047-1052. doi:10.2105/AJPH.2005.071910

[11] R. P. Nugent, M. A. Krohn and S. L. Hillier, "Reliability of Diagnosing Bacterial Vaginosis Is Improved by a Standardized Method of Gram Stain Interpretation,” Journal of Clinical Microbiology, Vol. 29, No. 2, 1991, pp. 297301.

[12] A. B. Moscicki, Y. Ma, C. Holland and S. H. Vermund, "Cervical Ectopy in Adolescent Girls with and without Human Immunodeficiency Virus Infection,” The Journal of Infectious Diseases, Vol. 183, No. 6, 2001, pp. 865870. doi:10.1086/319261

[13] D. Solomon, D. Davey, R. Kurman, A. Moriarty, D. O'Connor, M. Prey, S. Raab, M. Sherman, D. Wilbur, T. Wright Jr., N. Young and Forum Group Members, "Bethesda 2001 Workshop: Terminology for Reporting Results of Cervical Cytology," Journal of the American Medical Association, Vol. 287, No. 16, 2002, pp. 21142119. doi:10.1001/jama.287.16.2114

[14] N. Muñoz, F. X. Bosch, S. de Sanjosé, R. Herrero, X. Castellsagué, K. V. Shah, P. J. Snijders, C. J. Meijer and International Agency for Research on Cancer Multicenter Cervical Cancer Study Group, "Epidemiologic Classification of Human Papillomavirus Types Associated with Cervical Cancer," The New England Journal of Medicine, Vol. 348, No. 6, 2003, pp. 518-527. doi:10.1056/NEJMoa021641

[15] D. J. Jamieson, A. Duerr, R. Burk, R. S. Klein, P. Paramsothy, P. Schuman, S. Cu-Uvin, K. Shah and HIV Epidemiology Research Study (HERS) Group, "Characterization of Genital Human Papillomavirus Infection in Women Who Have or Who Are at Risk for Having HIV Infection,” American Journal of Obstetrics \& Gynecology, Vol. 186, No. 1, 2002, pp. 21-27. doi:10.1067/mob.2002.119776

[16] L. A. Denny, S. Franceschi, S. de Sanjosé, I. Heard, A. B. Moscicki and J. Palefsky, "Human Papillomavirus, Human Immunodeficiency Virus and Immunosuppression," Vaccine, Vol. 30, No. S5, 2012, pp. 168-174.
[17] H. De Vuyst, F. Lillo, N. Broutet and J. S. Smith, "HIV, Human Papillomavirus, and Cervical Neoplasia and Cancer in the Era of Highly Active Antiretroviral Therapy," European Journal of Cancer Prevention, Vol. 17, No. 6, 2008, pp. 545-554. doi:10.1097/CEJ.0b013e3282f75ea1

[18] L. S. Massad, K. A. Riester, K. M. Anastos, R. G. Fruchter, J. M. Palefsky, R. D. Burk, D. Burns, R. M. Greenblatt, L. I. Muderspach and P. Miotti, for Women's Interagency HIV Study Group "Prevalence and Predictors of Squamous Cell Abnormalities in Papanicolaou Smears from Women Infected with HIV-1," Acquired Immune Deficiency Syndrome, Vol. 21, No. 1, 1999, pp. 33-41. doi:10.1097/00126334-199905010-00005

[19] L. Ahdieh, R. S. Klein, R. Burk, S. Cu-Uvin, P. Schuman, A. Duerr, M. Safaeian, J. Astemborski, R. Daniel and K. Shah, "Prevalence, Incidence, and Type-Specific Persistence of Human Papillomavirus in Human Immunodeficiency Virus (HIV)-Positive and HIV-Negative Women," The Journal of Infectious Diseases, Vol. 184, No. 6, 2001, pp. 682-690. doi:10.1086/323081

[20] A. B. Moscicki, J. H. Ellenberg, S. Farhat and J. Xu, "Persistence of Human Papillomavirus Infection in HIVInfected and -Uninfected Adolescent Girls: Risk Factors and Differences, by Phylogenetic Type," The Journal of Infectious Diseases, Vol. 190, No. 1, 2004, pp. 37-45. doi:10.1086/421467

[21] S. Cauci, S. Guaschino, S. Driussi, D. De Santo, P. Lanzafame and F. Quadrifoglio, "Correlation of Local Interleukin-8 with Immunoglobulin A against Gardnerella vaginalis Hemolysin and with Prolidase and Sialidase Levels in Women with Bacterial Vaginosis,” The Journal of Infectious Diseases, Vol. 185. No. 11, 2002, pp. 16141620. doi: $10.1086 / 340417$

[22] P. E. Castle, S. L. Hillier, L. K. Rabe, A. Hildesheim, R. Herrero, M. C. Bratti, M. E. Sherman, R. D. Burk, A. C. Rodriguez, M. Alfaro, M. L. Hutchinson, J. Morales and M. Schiffman, "An Association of Cervical Inflammation with High-Grade Cervical Neoplasia in Women Infected with Oncogenic Human Papillomavirus (HPV)," Cancer Epidemiology, Biomarkers \& Prevention, Vol. 10, No. 10, 2001, pp. 1021-1027.

[23] A. B. Moscicki, N. Hills, S. Shiboski, K. Powell, N. Jay, E. Hanson, S. Miller, L. Clayton, S. Farhat, J. Broering, T. Darragh and J. Palefsky, "Risks for Incident Human Papillomavirus Infection and Low-Grade Squamous Intraepithelial Lesion Development in Young Females," Journal of the American Medical Association, Vol. 285, No. 23, 2001, pp. 2995-3002. doi:10.1001/jama.285.23.2995 